\title{
Rise of Augmented Reality: Current and Future Application Areas
}

\author{
Abrar Omar Alkhamisi, Muhammad Mostafa Monowar \\ Department of Information Technology, Faculty of Computing and Information Technology, \\ King AbdulAziz University, Jeddah, Saudi Arabia \\ Email: Abrar200828@yahoo.com, hemal.cu@gmail.com
}

Received August 30, 2013; revised October 4, 2013; accepted October 12, 2013

Copyright (C 2013 Abrar Omar Alkhamisi, Muhammad Mostafa Monowar. This is an open access article distributed under the Creative Commons Attribution License, which permits unrestricted use, distribution, and reproduction in any medium, provided the original work is properly cited.

\begin{abstract}
The massive technological advancements around the world have created significant challenging competition among companies where each of the companies tries to attract the customers using different techniques. One of the recent techniques is Augmented Reality (AR). The AR is a new technology which is capable of presenting possibilities that are difficult for other technologies to offer and meet. Nowadays, numerous augmented reality applications have been used in the industry of different kinds and disseminated all over the world. AR will really alter the way individuals view the world. The AR is yet in its initial phases of research and development at different colleges and high-tech institutes. Throughout the last years, AR apps became transportable and generally available on various devices. Besides, AR begins to occupy its place in our audio-visual media and to be used in various fields in our life in tangible and exciting ways such as news, sports and is used in many domains in our life such as electronic commerce, promotion, design, and business. In addition, AR is used to facilitate the learning whereas it enables students to access location-specific information provided through various sources. Such growth and spread of AR applications pushes organizations to compete one another, and every one of them exerts its best to gain the customers. This paper provides a comprehensive study of AR including its history, architecture, applications, current challenges and future trends.
\end{abstract}

Keywords: Augmented Reality; Virtual Reality; Augmented Reality Browser; Mobile Augmented Reality

\section{Introduction}

The technological advances have a direct effect on our life and on our behavioral manner. The Augmented reality moves from the industrial niches to mass technology [1]. It can be defined as an emergent form of practice, through which the real world is improved through computer generated content that is connected to particular places and/or events. In other words, AR permits the digital content to be effortlessly superimposed and intermingled into our insights and conception of the real world [2].

Augmented reality can be described as one of the technologies that can develop a "next generation, realitybased interface" [3]. Also, it is distinguished by promotion from just being in test centers around the world to being used in different fields and consumer markets. Nowadays with the emergence and diffusion of the smart phones and AR browsers, we begin to accept this different and exciting type of human-computer communication
[3]. In spite of the fact that AR has gained much more research interest and attention recently, various meanings are attached to the term AR by researchers. Besides, AR could be developed through using and involving different inventive technologies (for instance, body-borne computers, mobile phones, and immersive technologies) [4].

During the last years, the AR applications have turned out to be transportable and broadly accessible on mobile phones. Also, the AR has become one of our audio-visual media (for instance, news, means of entertainment and sports). In addition, it is being used recently in many fields such as electronic commerce, tourism and promotion. Besides, it has turned to be a very significant part of the Virtual Reality (VR) domain. The AR enjoys clear advantages in comparison to the traditional VR. One of the key advantages gained by AR is having a better sense and interaction of reality whereas it lays emphasis on the organic integration of virtual environment and the real world [1]. 
In this article we present a survey of the state of the art in AR. Our aim is to provide a better understanding of the current and future application areas in this emerging field. The remainder of this paper is organized as follows: Section 2 presents an overview of AR, Section 3 reviews AR throughout history, Section 4 describes the architecture of AR system, Section 5 discusses about different applications of AR, Section 6 summarizes the current challenges of AR, Section 7 discusses the future trends of AR, and finally Section 8 concludes the paper.

\section{Augmented Reality: An Overview}

Augmented reality (AR) can be defined as able to deal with the new information immediately direct or indirect therefore influence the physical real-world environment has been enhanced/augmented were by adding virtual computer-generated information to it $[5,6]$.

Also, the AR is defined by Azuma in 1997 [7]. He indicates that the AR is not only restricted to the technical hardware whereas it brings the real and virtual items together in a real environment. In addition, it records the real and virtual objects together and then runs jointly in real time in three dimensions.

Milgram and Kishino [2] defined the continuum of reality-virtuality where AR is considered a portion of the overall subject area of mixed reality. Both virtual environments and augmented virtuality where the real items are sub-joined to the virtual ones can substitute the adjacent environment by a virtual one. On the contrary, the local virtuality is submitter by the augmented reality .As shown in Figure 1.

The goal of the AR is to make the life of the user easier through providing the virtual information to his adjacent environment as well as to any indirect view of the real-world environment like the live-video stream. Another goal of AR is to develop the user's insight into and communications with the real world. The virtual reality or the virtual environment as named by Milgram engages users totally in an artificial world without seeing the real one. On the other hand, the augmented reality boosts the sense of reality through laying virtual items over the real world in real time. AR not only adds items in real word but also represents useful digital information in real world $[5,6]$.

\section{Augmented Reality throughout History}

The term augmented reality appears for the first time in

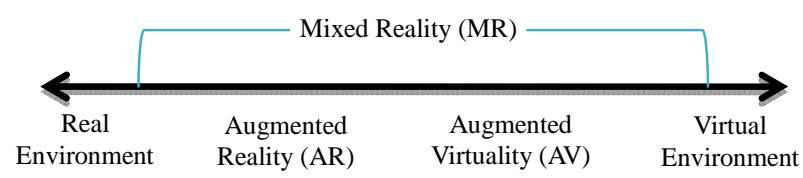

Figure 1. Reality-virtuality consecutive [5]. 1950s when Morton Heilig, a motion-picture cameraman, believed that cinema as an art should be capable of drawing the watcher into the on screen activity. In 1962, Heilig developed a model of his idea, that he termed in 1955 as "The Cinema of the Future", known as Sensorama, which exist before digital computing [5]. Then, Ivan Sutherland devised the head mounted in 1966 [2,5]. While in 1968, he developed a working prototype of the first AR system [2]. After that Myron Krueger in 1975 established an artificial reality laboratory called video place. It is an area which enables users to easily deal with the virtual elements for the first time [5,6].

At the beginning of 1990s, AR became a field of study. In 1997, Ronald Azuma conducted the first survey in AR whereas he introduced a broadly accepted definition of AR. He defined it as assembling real and virtual environment together while both of them is being recorded in $3 \mathrm{D}$ and interactive in real time [5,7]. In 2000, Bruce Thomas invented the first mobile AR game and displayed it during the International Symposium on Wearable Computers [5,6]. In 2007 new medical applications were developed. After that, more AR applications are designed particularly with mobile applications e.g. Wikitude AR Travel Guide was created in 2008 [5]. In 2008, Gartner Inc. expected that AR would be among the first 10 troublemaking technologies in the period from 2008 to 2012 [2]. In addition, it is clear that the number of AR accessible apps have been augmented suddenly and expanded to include not only the location-based search apps but also social networking, games, instructive, lifestyle and individual healthcare apps [7]. Figure 2 shows the evolution of augmented reality throughout the history.

\section{Architecture of the Augmented Reality System}

The four tasks carried out by the AR system are: scene capture; scene identification for choosing the accurate information for boosting it; scene processing and visualization of the augmented scene $[8,9]$. These tasks are described in details as follows:

\subsection{Scene Capture}

Generally, the devices used in scene capture are physical components which recognize the reality which should be boosted. There are two types of scene capture devices:

- Video-through devices: Such devices capture the reality in a different way than the other devices used for visualizing the augmented reality (for instance, video cameras, and smart phones) [9].

- See-through devices: Such devices capture reality and give a picture of it with the augmented information (for instance, head mounted displays) [9]. 


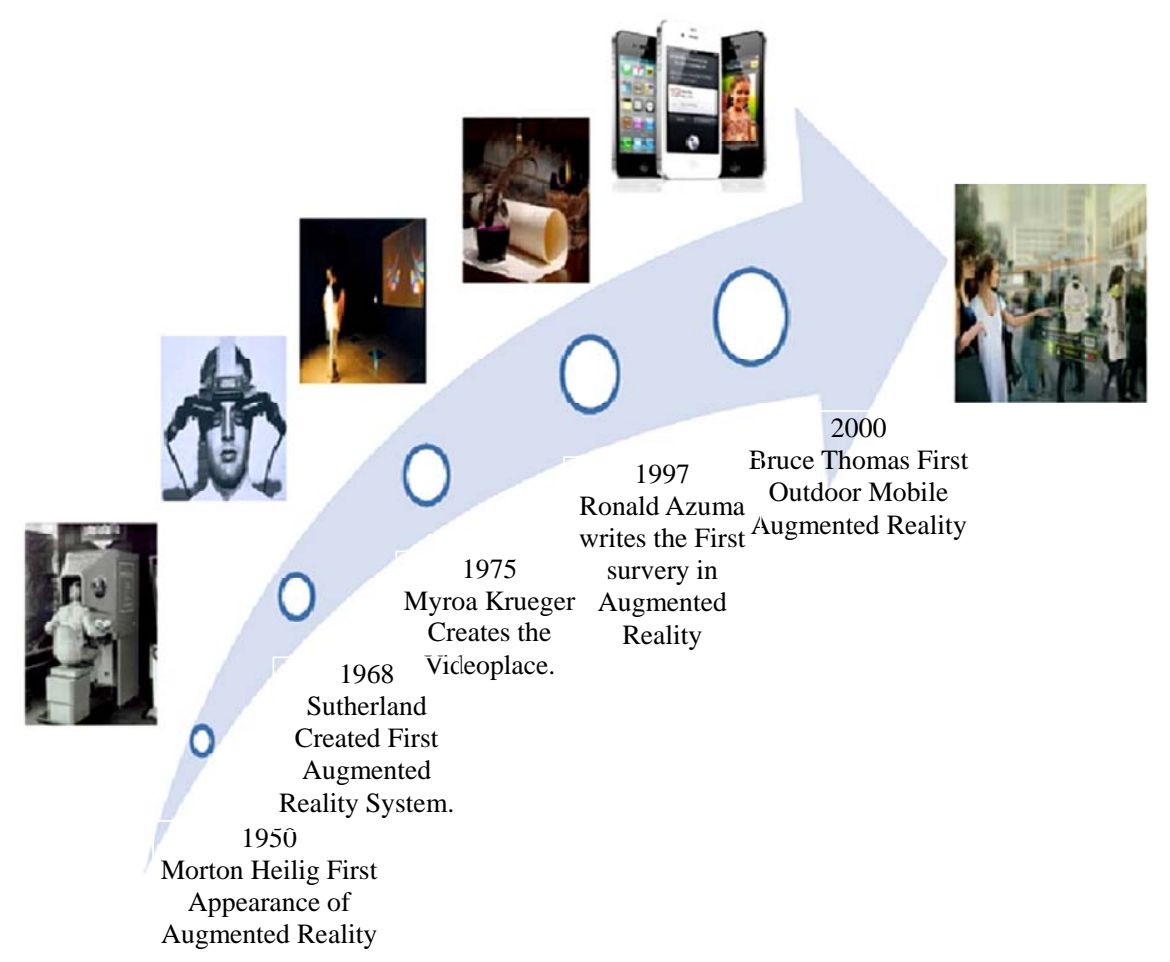

Figure 2. Augmented reality throughout history.

\subsection{Scene Identification Techniques}

Scene identification classifies the scenarios. Also, it is considered one of the main actions taken in reality augmentation. There are two basic types of scene identification techniques which are discussed as follows:

- Marker-based: The marker-based approach uses the markers which are in the form of visual tags contained within the real scene which is perceived by the AR system [9]. Figure 3 shows the example of marker.

- Non-marker-based: AR systems which do not utilize markers make use of devices for scene identification. Such as AR browser uses tags in order to help users envisage and surf digital data in real world environment. For instance, you may go around the town searching for your preferred restaurant. Through the video feature that exists in your AR browser, you can easily find the restaurant you search for instead of having a look on a map. In addition, as long as you

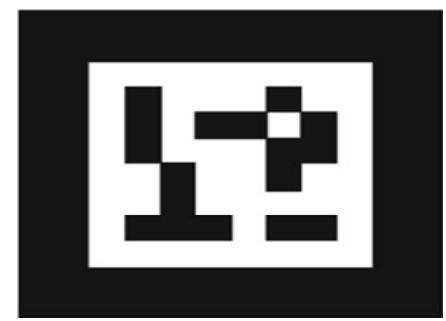

Figure 3. Example of marker [10]. move around, the browser can easily give information concerning your place, e.g. the specific point location you are interested in, clinics, restaurants, etc. [11]. AS shown in Figure 4.

\subsection{Scene Processing}

After calculating the spot of a specific marker in real space according to inner and outer parameters of the camera, the system looks for the corresponding virtual model to each marker in the 3D.

\subsection{Visualization Scene}

At the end, the system produces the image of the projected 3D object and real space and passes on the scene image that mixes reality and virtuality in case using mar-

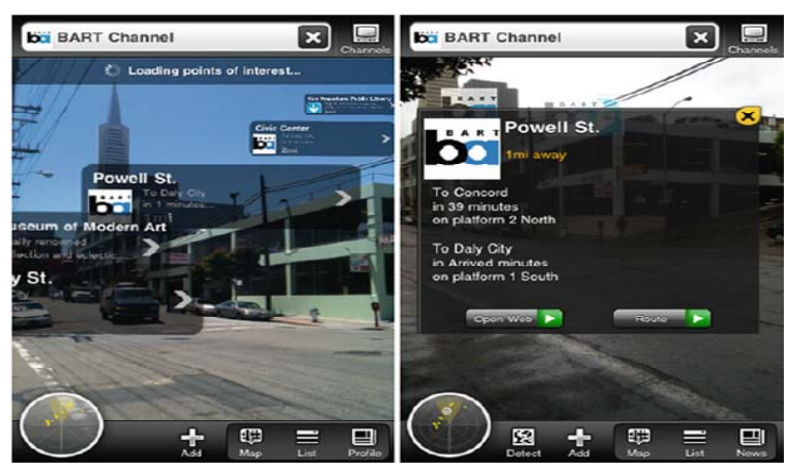

Figure 4. Example of non-marker [10]. 
ker and present digital information when used non marker scene of identification techniques [8].

\section{Applications of Augmented Reality}

The number of applications utilizing augmented reality is increasing continuously and the outcomes are clear in many domains e.g. health care, business, education and amusement. This section concerns with summarizing the prior researches that exploit the augmented reality applications.

\subsection{Medical}

\subsubsection{Medical Learning}

It is well known that AR has presented new ways of submitting information. The health care world would be reorganized to be represented in a mobile AR way. Such health related information can be submitted by AR in its extreme visual. The AR became widespread by virtue of the smartphones that are supplied with sensors and camera. Such sensors permit the provision of precise context information to the environment aware situations, the matter that permits doctors to gather information, illustrate and identify the measures and procedures. Also, doctors can easily have control over the sick persons needing constant intensive care, e.g. measuring the temperature and heartbeats, etc. This information can be submitted through the AR. As indicated in Figure 5 of apps utilizing AR in medical school [12].

\subsubsection{Medical Training}

AR has had great implications for the medical industry; however, its more innovative apps come about because of the popular usage of mobile technology. AR is considered very beneficial in the field of healthcare training. For example, the healthcare provider can easily install a program or an application on his mobile. Such program or application may contain the main list of medical measures for the healthcare providers to select from. Once the healthcare provider chooses one of the measures from the list, the first screen will display where the tracking patterns should be situated in the sick person's body. After applying the patterns, the training model will begin.

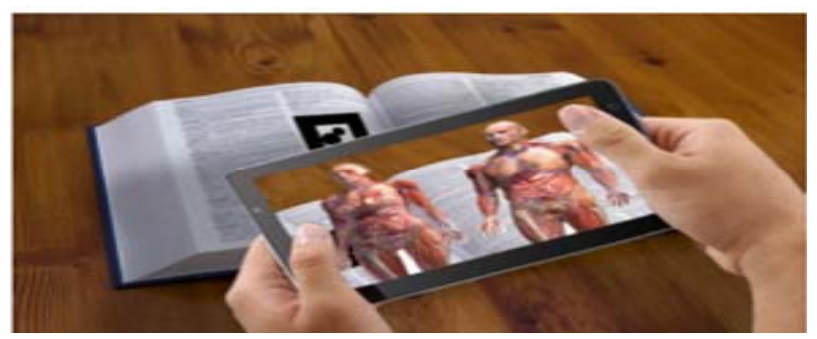

Figure 5. Example of augmented reality medical school practical books from student view on phone display [12].
The training program will show an animated simulation in $3 \mathrm{D}$, indicating precisely when, where, and in what the various maneuvers should be performed. Also, the user can alter the point of view of the simulation through moving the mobile phone, either forwards or backwards, via the animation. In addition, he can display extra notices in the course of particular points of the measures [13]. As indicated in Figure 6 one of apps utilizing AR in medical training.

\subsection{Education}

\subsubsection{E-book}

This application depicts a physical interface (augmented book) relying on augmented reality technology for learning standard mechanical components. Such book has been contained in the course of an engineering graphics subject in a mechanical engineering degree of a Spanish university [14]. Figure 7 depicts the augmented book.

\subsubsection{Children Education}

- FETCH! Lunch Rush is defined as an AR application
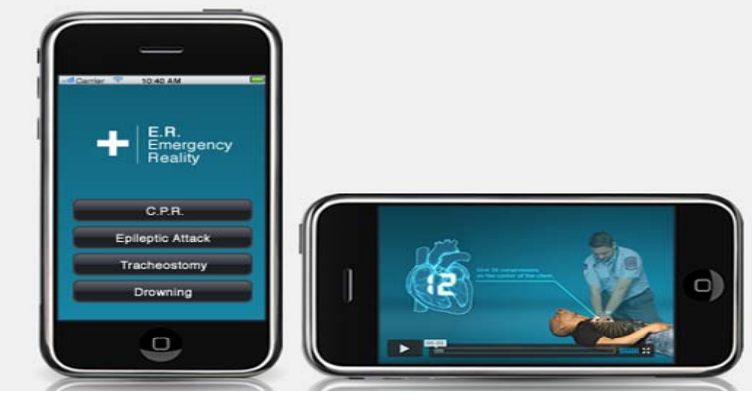

Figure 6. Example of augmented reality training.

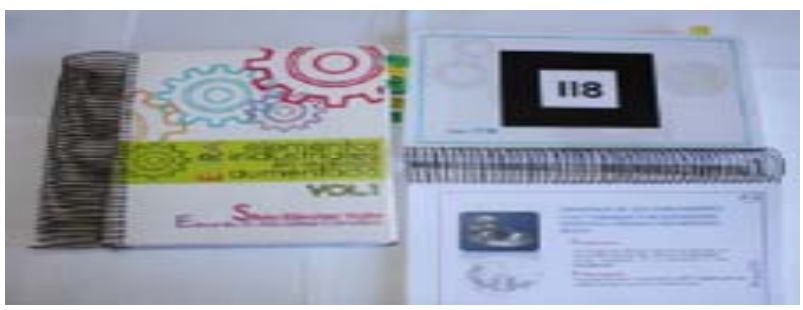

(a)

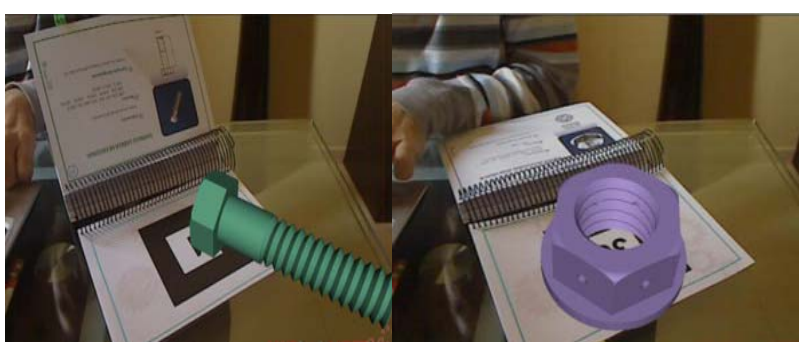

(b)

(c)

Figure 7. (a) Augmented book; (b) Examples of hex-head screw; (c) Examples hex-nut perforated [14]. 
that is concerned with teaching mathematical proficiencies to primary pupils via making use of visualization. Designed in 3-D, the application utilizes in smartphone camera to place photos on your camera over real-world surroundings. After that, the application instructs primary pupils to add and subtract through utilizing real-world situations that permits visualization at the time of solving mathematical problems [15]. Figure 8 depicts the FETCH Lunch Rush application.

- Matching Objects and Words: Nowadays, digital games have been designed not only for amusement but also to boost the learning process. Matching Objects and Words (MOW) application is an AR game that is designed and developed to help learning words in various languages [16]. Figure 9 illustrates an example of how it works.

\subsection{Commerce}

\subsubsection{Mobile Coupons}

Nowadays, mobile coupons have become a tendency

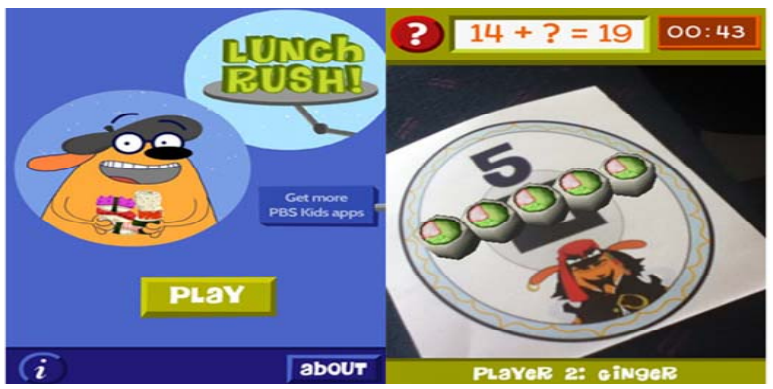

Figure 8. FETCH lunch rush application [15].

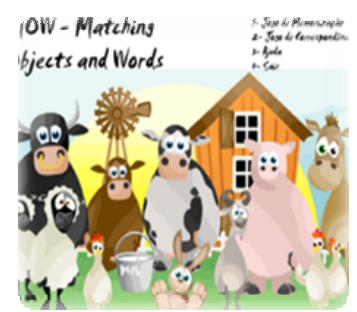

(a)
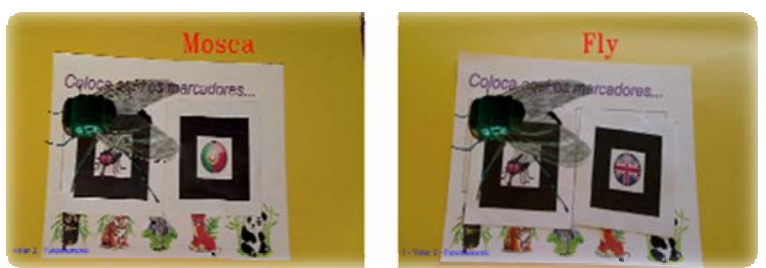

(c)

Figure 9. (a) MOW start menu; (b) Examples of template markers used in MOW; (c) Game 1 being played with Portuguese (left image) and English (right image) words [16]. among customers. For customers, it was impractical dream to go to the retail store and to have all the coupon deals forwarded directly to your mobile device. Hence, the mobile coupon becomes an important instrument. With the development of AR technology, users became capable of getting good local deals around their particular places [10] as shown in Figure 10.

\subsubsection{Clothing Shopping}

E-commerce is considered as one of the most beneficial applications of the AR apps. Specifically on line clothing shopping due to the users cannot predict whether the clothes will fit them or not. Hence, individuals start to connect AR with electronic shopping, e.g. clothing shopping. This step helps to get overcome a biggest obstacle users face in choose clothing and at the same time improve the quality level and competitiveness of this business to new levels [17] as shown in Figure 11.

\subsubsection{Products Shopping}

AR apps provide customers with valuable content. This content may tackle the product characteristics and advantages or may provide information that assists customers to make a comparison between the different types of

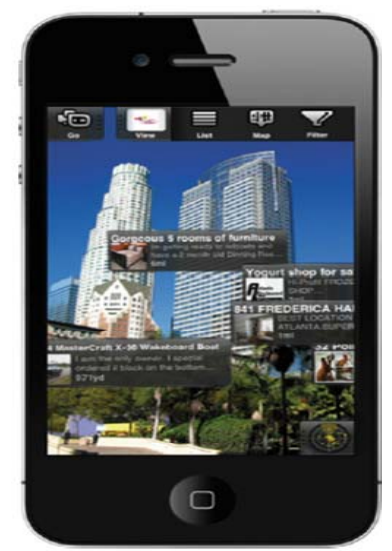

Figure 10. Mobile coupons application classifieds offers [10].

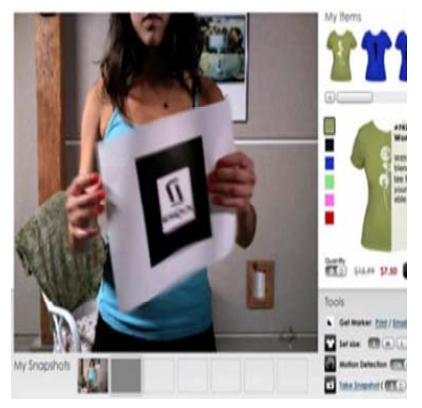

(a)

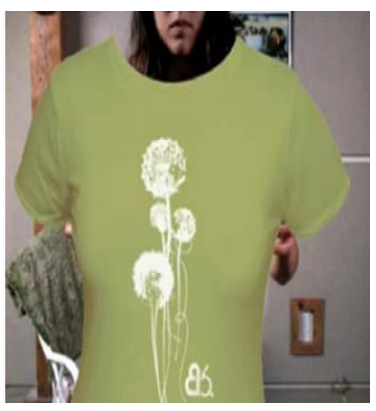

(b)
Figure 11. (a) Application search for the marker; (b) Marker replacement with a virtual object [17]. 
products and hence take the best shopping decisions [18].

For example when the consumer who suffers from health problems wants to buy cereals but there are many brands to choose from, he can easily tap an AR app to know all the products relevant in this information and thus can easily compare between the different brands and choose the best one for him [18] as shown in Figure 12.

\subsubsection{Shopper Browsing through Different Reviewers}

Buyers depend greatly on web-based social content, e.g. product reviews, before buying any products. The latest surveys conducted on the Retail Industry affirm the importance of the social content where as it is considered the first element relied on before taking the purchase decision. Nowadays, this web-based content warehouse is only reachable by computers that are far removed from the place of shopping experience itself. A mobile AR application outspreads this social content from the computer display to the real world via mobile devices, supplying customers with products related information that helps them to realize the suitable time for taking the purchase decision [19] as shown in Figure 13.

\subsection{Advertising}

\subsubsection{Image Space Application}

Since the smart phones are provided with multimedia devices, e.g. many sensors, they are considered the perfect enablers for AR whereas they enable users to catch sight of the real world via a magic lens. The "Image Space"

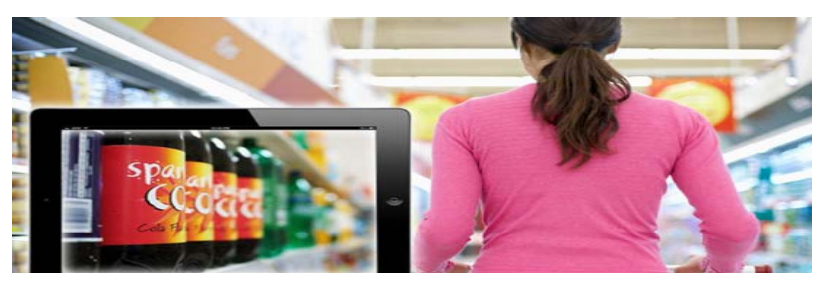

Figure 12. Mobile trends for products shopping [18].

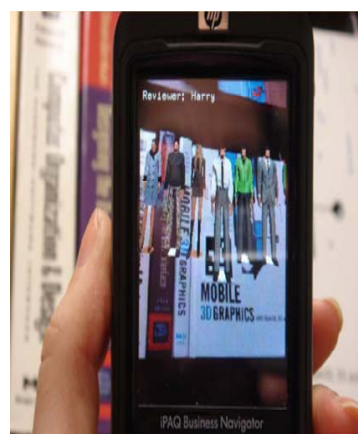

(a)

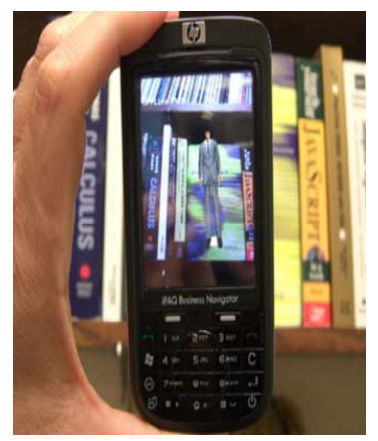

(b)
Figure 13. (a) Shopper browsing through different reviewers; (b) Shopper focusing on one reviewer while browsing through books on a shelf [19]. application indicates the manner through which users and small companies can present their content, advertising to AR view, without exerting great efforts, therefore, this content can be accessed immediately by any user who installed the Image Space mobile client on his mobile. As presented in the screen capture of our mobile client as indicated in Figure 14, the live camera feed displays the real world when on the other hand the digital banner is overlapped on the upper part, making it appears as "standing" in front the store, even though the user switches the device [20].

\subsubsection{Advertisers Print Media Campaigns}

Throughout the last year, several brands have utilized AR to promote and market their products, e.g. LEGO, JC Penny, Adidas, etc. Regardless of the application type, e.g. online, or mobile applications, they all have been designed in such a way that involves the user in a more collaborative way rather than the traditional marketing. Nowadays, mobile augmented reality (known as MAR) makes it possible for sellers and advertisers to improve their print advertisements in their portfolio of media plan tactics. Recently, many companies, such as Coca Cola in Germany and Absolut Vodka in Spain, make user of MAR in order to add extra dimension and zest their current printed advertisements [21] as shown in Figure 15.

\subsection{Entertainment}

\subsubsection{Tangible Cubes}

This application offers an AR game which aims at learning about animals in danger of extinction in amusing way. This application depends on utilizing tangible cubes

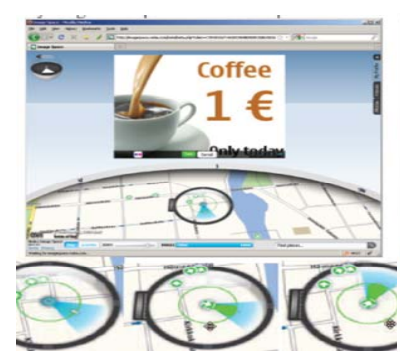

(a)

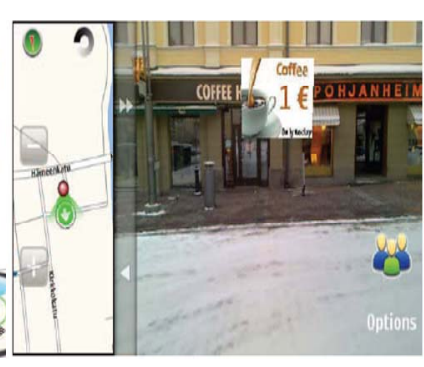

(b)
Figure 14. (a) Placing the banner on a map; (b) Example of a coffee store banner in the augmented reality client [20].



Figure 15. Advertisers print using augmented reality [21]. 
as the user interface as indicated in Figure 16. Through this app, children know much information about the animals' characteristics and habits and reasons of probable extinction [22].

\subsubsection{Sightseeing Guidance}

Through this app, users can easily publish and share sightseeing information through making use of mobile devices. Hence, this app will assist users to enhance sightseeing information. Moreover, the suggested application system utilizes AR which boosts the real environment with computer-generated objects. Consequently, the application system can be utilized as a sightseeing guidance system that overlays annotations on a real world. Particularly, the suggested application system submits virtual tour guides in order to help their tour [23] as indicated in Figures 17-19.

\subsection{Design}

\subsubsection{Machinery Systems Design}

The machinery systems design is one of the AR applications which are concerned with enhancing product design and development. This application focuses on a different engineering instrument. Hence, design and its related matters are submitted in a limited way. It is probable to

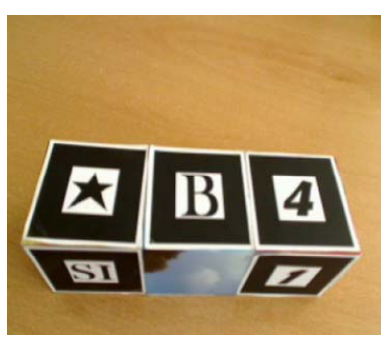

(a)

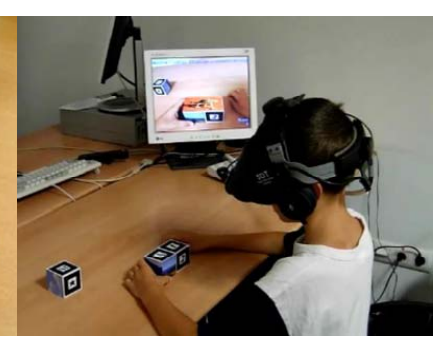

(b)
Figure 16. (a) The three cubes used in the game; (b) A boy is trying to find the Orinoco crocodile in game [22].

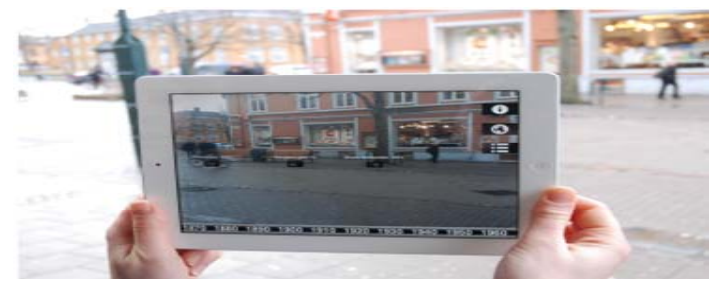

Figure 17. Augmented reality view [24].

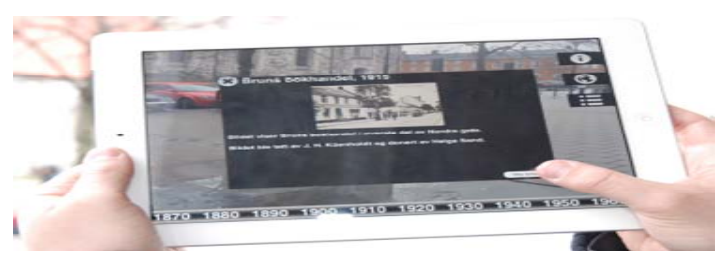

Figure 18. Detailed information view [24]. utilize the AR technology in design, with the desire that in sometime in the future it may become a complementary part of a standard design process of more dependable and resilient machinery systems. The basic aim of the applied application was to help designers of machinery system to design more dependable mobile robots. Knowledge embodied in a procedural form should be utilized during the design process in order to remove causes of incompetence in the upcoming products. Such knowledge is stored in a knowledge database which is gained from experts [25] as indicated in Figure 20.

\subsubsection{Furniture Design}

Having a good application will enable you to reorganize the chamber while sitting down on your sofa. With the AR application, you can easily see the general view of the new furniture in the sitting room or you can know the suitable color for the office. AR is considered an amazing notion which can easily deliver virtual furniture into our houses. Also, this application can arrange the new furniture in your house on screen in real time. In addition, it can easily alter the color, size, and location of every piece for full customization [26] as indicated in Figure 21.

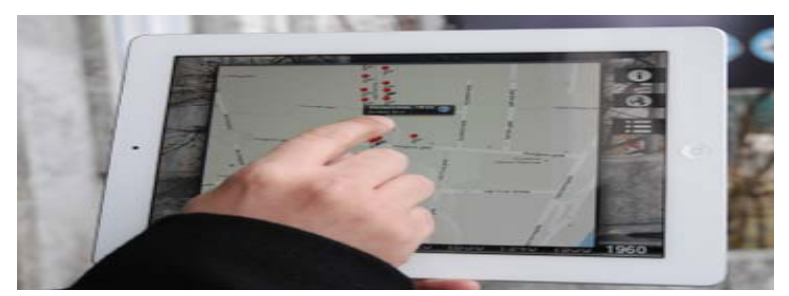

Figure 19. Map [24].

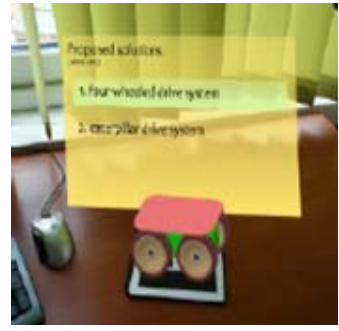

(a)

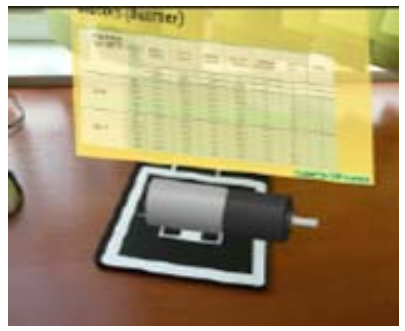

(b)

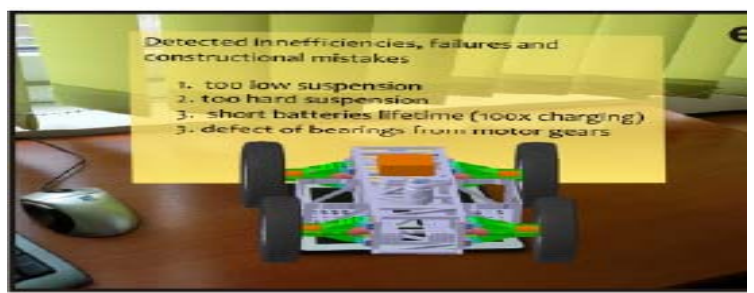

(c)

Figure 20. (a) \& (b) Previewing data from a database; (c) Viewing instructions or procedures concerning design process [25]. 


\section{Current Challenges of Augmented Reality}

In this section, the current challenges facing augmented reality are described. They are classified as follows:

\subsection{Environment}

There are some perceptual matters associated with the environment itself. Such matters can cause further problems through the interaction between the environment and the augmentations [27]. The most important challenges facing the environment are as follows:

- Lighting and weather conditions unfortunately, it is indicated that in outside environments, many of the features existing in natural pictures are not connected to real physical features. Shadows caused by light being blocked by objects in the scene help corners and lines to occur and to move as lighting or climate conditions change. Consequently, a large number of outliners and divergences influence localization quality, regardless of selecting corresponding algorithm [28].

- The color scheme and diversity of an environment can hamper accurate perception on the whole and result in major problems while illustrating it. In addition, the color scheme of an environment would cause major problems in the light conditions variation. At last, surfaces with high color variances would influence the reflectiveness of projected images in projector-camera systems [27].

\subsection{Display Device}

There are some technical problems connected with the display device [27]. They are as follows:

- Camera quality and handling in the light of bad lighting conditions, the imaging competences of camera sensors that are being widespread in devices become poor. Pictures are fuzzy and colors begin to undergo significant aberration [28].

- Color fidelity in outside environments is considered an extremely difficult issue. Altering the external conditions greatly influence optical see-through displays than video see-through displays, whereas in video see-through both the real world and the overlays are

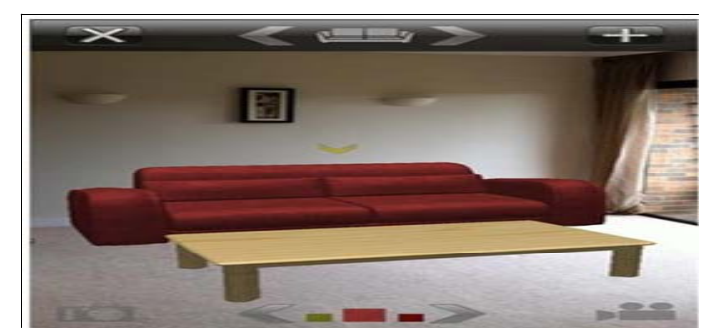

Figure 21. Home design interior space using augmented reality [26]. presented in the same color gamut [27].

Still, there are some major challenges even with the much more developed hardware. Hence, we conclude that we are not completely capable of utilizing AR as a commonly feature existing on smartphones.

\subsection{Content Management}

A lot of the current handheld AR systems are incomplete on the way of attaching the new content to them. In general, such systems are controlled by a small number of professional domains. The authority to add new content is only given to application developers, and this is available through the backend of the application due to the need of programming skills to make a link between current systems and data sources. The regular users, visitors and/or businessmen, in mobile AR systems, should have the ability to add their personal content without spending great technical efforts. Moreover, there is a user created feature in these systems, which is presenting a way that is easy for all users to mash up the content they have already created from various sources into an identical handheld AR view [29].

\subsection{User}

There are also some user concerns which could be a challenge for AR. The Location of the users is considered a central element of any AR system [28].

\section{Future Trends of Augmented Reality}

AR is still in its initial phases; consequently, its upcoming potential applications are never-ending. Advanced research in AR takes account of suggests for an era where the interaction between individuals and information is done in a straight line without needing the utilization of any halfway device. As shown in Figure 22, MIT Media Lab project "Sixth Sense" is the best model of AR research and Parviz's contact lens project proposal find environment where information can only be viewed by the user [5].

Moreover, augmented reality provides an opportunity to replace and remedy the absent senses for some impaired individuals, i.e. AR could be utilized as a sense alternate instrument. Hearing-impaired individuals could be given visual signals guiding them to catch missed aural signals and sightless individuals could be given aural signals guiding them to unknown visual events [6]. An additional in future some AR applications are not far from challenges social acceptance issues, privacy concerns, and ethical concern arising [6].

Alternatively, a small number of related studies have been prepared for the approval and the usability of AR systems and innovations in manufacturing instructions and training that require additional investigations and 


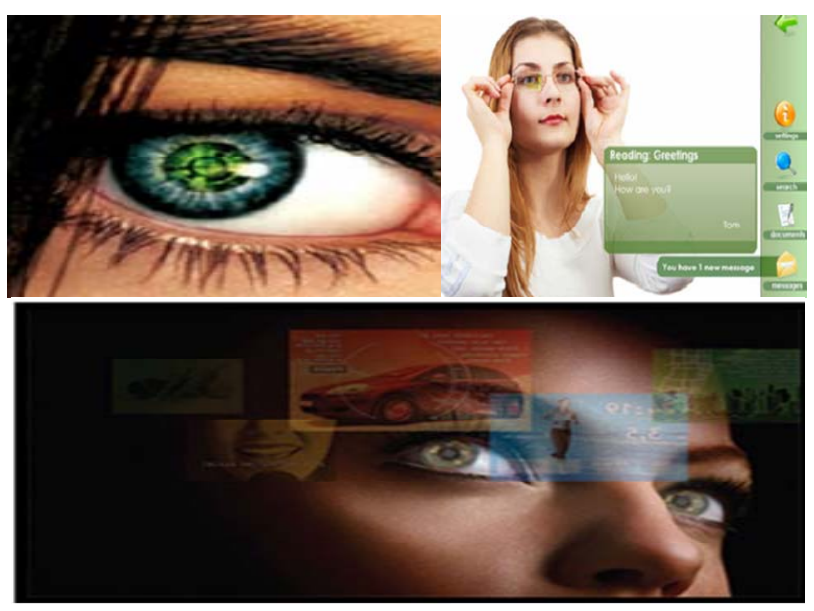

Figure 22. Example of futuristic augmented reality [5].

research in future. Nonetheless, since many experts and researchers positively declared the potential likelihood of $\mathrm{AR}$ in industrial and commercial fields in their studies, $\mathrm{AR}$ in manufacturing venues has an opportunity for the growth of its extent into other business fields such as manufacturing, services, government-related sections, and other industrial settings. Along with such sections, appears a good opportunity of AR to be experienced in occupational safety and health (OSH) sectors. AR could be assumed into safety check up in power plants, chemical plants, and oil refineries, OSH training for executives and members of staff with computer-generated 3D settings, as well as AR games and simulations about dangerous resources management [2].

An additional app provided by application developer Crowd Optic may head for a new development in augmented reality apps. This new technology of Crowd Optic put fans gathering like shows or sports events in focus [30].

In the future augmented reality will provide opportunities for businesses and dealers to spend their money and efforts in new fields of AR. The researchers expected all augmented reality applications returns will come up to $\$ 5155.92$ million by 2016 [31]. Also, as shown in Figure 23 the total mobile AR revenues from 2012 to 2017 will be come up to $\$ 5.2$ billion on mobile devices split by different categories of application [32].

\section{Conclusion}

Augmented reality is considered a competence that has been around for years. Augmented reality is still in its initial phases; and thus the upcoming possible apps are endless. A lot of AR products have been presented in several kinds and spread around the world. The layering of information over 3D space creates completely new experiences of the world, and supports the broader transition of computing from the desktop to the mobile

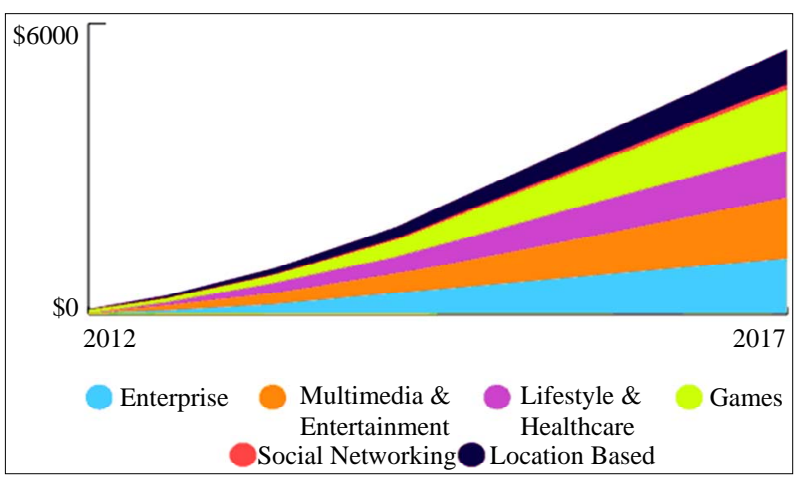

Figure 23. Revenues of augmented reality mobile application from 2012 to 2017 [32].

devices, and at the same time raising new outlook concerning reaching information and new chances for learning. In spite of the fact that AR is utilized broadly in the customers sector, for example it is used in social engagement, entertainment and marketing, new forms of usage appear every day. It can be easily utilized as a tool for developing new apps. In addition, AR will be more accessible in the recently future and it will be a complementary part in our lives.

\section{REFERENCES}

[1] R. Yang, "The Study and Improvement of Augmented Reality Based on Feature Matching,” 2011 IEEE 2nd International Conference on Software Engineering and Service Science (ICSESS), Beijing, 15-17 July 2011, pp. 586589.

[2] S. C.-Y. Yuen, G. Yaoyuneyong and E. Johnson, “Augmented Reality: An Overview and Five Directions for AR in Education,” Journal of Educational Technology Development and Exchange, Vol. 4, No. 1, 2011, pp. 119-140.

[3] D. Krevelen and R. Poelman, "A Survey of Augmented Reality Technologies, Applications and Limitations,” The International Journal of Virtual Reality, Vol. 9, No. 2, 2010, pp. 1-20.

[4] H. Wu, S. Wen-Yu, H. Chang and J. Liang, "Current Status, Opportunities and Challenges of Augmented Reality in Education,” Computers \& Education, Vol. 62, 2013, pp. 41-49. http://dx.doi.org/10.1016/j.compedu.2012.10.024

[5] J. Carmigniani, B. Furht, M. Anisetti, P. Ceravolo, E. Damiani and M. Ivkovic, "Augmented Reality Technologies, Systems and Applications,” Multimedia Tools and Applications, Vol. 51, No. 1, 2011, pp. 341-377. http://dx.doi.org/10.1007/s11042-010-0660-6

[6] J. Carmigniani and B. Furht, "Augmented Reality: An Overview” In: J. Carmigniani and B. Furht, Eds., Handbook of Augmented Reality, Springer, New York, 2011, pp. 3-46. http://dx.doi.org/10.1007/978-1-4614-0064-6_1

[7] J. Ford and T. Höllerer, "Augmented Reality and the Future of Virtual Workspaces,” In: Handbook of Research on Virtual Workplaces and the New Nature of Business 
Practices, IGI Global, Santa Barbara, 2008, pp. 486-502.

[8] S. Cai, X. Wang, M. Gao and S. Yu, "Simulation Teaching in 3D Augmented Reality Environment,” 2012 IIAI International Conference on Advanced Applied Informatics (IIAIAAI), Fukuoka, 20-22 September 2012, pp. 8388.

[9] H. López, A. Navarro and J. Relaño, “An Analysis of Augmented Reality Systems,” 2010 Fifth International Multi-Conference on Computing in the Global Information Technology (ICCGI 2010), 20-25 September 2010, Valencia, pp. 245-250.

[10] T. Jackson, F. Angermann and P. Meier, "Survey of Use Cases for Mobile Augmented Reality Browsers,” In: T. Jackson, F. Angermann and P. Meier, Eds., Handbook of Augmented Reality, Springer New York, 2011, pp. 409431.

[11] R. Grasset, T. Langlotz, D. Kalkofen, M. Tatzgern and D. Schmalstieg, "Image-Driven View Management for Augmented Reality Browsers," 2012 IEEE International Symposium on Mixed and Augmented Reality (ISMAR), Atlanta, 5-8 November 2012, pp. 177-186.

[12] Z. Mohana, I. Musae, M. A. Tahir, B. Parhizkar, A. Ramachandran and A. Habibi, "Ubiquitous Medical Learning Using Augmented Reality Based on Cognitive Information Theory," Advances in Computer Science, Engineering \& Applications, Vol. 167, 2012, pp. 305312. http://dx.doi.org/10.1007/978-3-642-30111-7_29

[13] J. Echeverry and D. Méndez, “Augmented Reality Training," 2010.

http://www.fabiangarzon.com/ar_training_2010.html

[14] J. Gutiérrez, "Proposal of Methodology for Learning of Standard Mechanical Elements Using Augmented Reality," ASEE/IEEE Frontiers in Education Conference, Rapid City, 12-15 October 2011, pp. 1-6.

[15] H. Lim, “5 Top Augmented Reality Apps for Education,” 2012.

http://www.hongkiat.com/blog/augmented-reality-apps-fo r-education/

[16] J. Barreira, M. Bessa, L. Pereira, T. Adao, E. Peres and L. Magalhaes, "MOW: Augmented Reality Game to Learn Words in Different Languages: Case Study: Learning English Names of Animals in Elementary School," 7th Iberian Conference on Information Systems and Technologies (CISTI), Madrid, 20-23 June 2012, pp. 1-6.

[17] F. Pereira, C. Silva and M. Alves, "Virtual Fitting Room Augmented Reality Techniques for e-Commerce," ENTERprise Information Systems, Communications in Computer and Information Science, Vol. 220, 2011, pp. 62-71.

[18] L. Goldstein, “DailyFinance,” 2013. http://www.dailyfinance.com/photos/mobile-shopping-tre nds/\#slide $=4956588$

[19] S. Guven, O. Oda, M. Podlaseck, H. Stavropoulos, S. Kolluri and G. Pingali, "Social Mobile Augmented Reality for Retail,” IEEE International Conference on Pervasive Computing and Communications, PerCom 2009, 913 March 2009, pp. 1-3.

[20] P. Belimpasakis, Y. You and P. Selonen, "Enabling Rapid Creation of Content for Consumption in Mobile Augmented Reality,” 2010 Fourth International Conference on Next Generation Mobile Applications, Services and Technologies (NGMAST), Amman, 27-29 July 2010, pp. 1-6. http://dx.doi.org/10.1109/NGMAST.2010.13

[21] Lisa, “Augmented Reality Enhances Brand/ Advertisers' Print Media Campaigns,” 2010. http://junaio.wordpress.com/2010/11/03/augmented-realityenhances-brand-advertisers-print-media-campaigns/

[22] C. Juan, G. Toffetti, F. Abad and J. Cano, "Tangible Cubes Used as the User Interface in an Augmented Reality Game for Edutainment," 2010 IEEE 10th International Conference on Advanced Learning Technologies (ICALT), Sousse, 5-7 July 2010, pp. 599-603.

[23] H. Furata, K. Takahashi, K. Nakatsu, K. Ishibashi and M. Aira, "A Mobile Application System for Sightseeing Guidance Using Augmented Reality,” 2012 Joint 6th International Conference on Soft Computing and Intelligent Systems (SCIS) and 13th International Symposium on Advanced Intelligent Systems (ISIS), Kobe, 20-24 November 2012, pp. 1903-1906.

[24] A, Haugstvedt and J. Krogstie, "Mobile Augmented Reality for Cultural Heritage: A Technology Acceptance Study," 2012 IEEE International Symposium on Mixed and Augmented Reality (ISMAR), Atlanta, 5-8 November 2012, pp. 247-255.

[25] M. Januszka and W. Moczulskia, “Augmented Reality for Machinery Systems Design and Development," New World Situation: New Directions in Concurrent Engineering, 2010, pp. 79-86.

[26] Apartment Therapy, “6 Interior Design Apps Offer Help with a Swipe,” 2013.

http://www.apartmenttherapy.com/6-home-design-apps-w eekly-smartphone-app-roundup-167368

[27] E. Kruijff, E. Swan and S. Feiner, "Perceptual Issues in Augmented Reality Revisited," 2010 9th IEEE International Symposium on Mixed and Augmented Reality (ISMAR), Seoul, 13-16 October 2010, pp. 3-12.

[28] C. Arth and D. Schmalstieg, "Challenges of Large-Scale Augmented Reality on Smartphones," Graz University of Technology, Graz, 2011, pp. 1-4.

[29] S. Kurkovsky, R. Koshy, V. Novak and P. Szul, "Current Issues in Handheld Augmented Reality,” 2012 International Conference on Communications and Information Technology (ICCIT), Hammamet, 26-28 June 2012, pp. 68-72.

[30] M. Samuels, "Future IT Trends: Experts Pick out Their Top Tips,” 2012.

http://www.techrepublic.com/blog/cio-insights/future-it-tr ends-experts-pick-out-their-top-tips/39749191

[31] Markets and Markets, "Virtual Reality \& Augmented Reality Market Forecast by Product (HMD, HUD, Tablet PC, Smartphone) for Gaming, Automotive, Medical, Advertisement, Defense, E-learning \& GPS Applications (20112016),” 2013.

http://www.marketsandmarkets.com/Market-Reports/realityapplications-market-458.html

[32] [x]cube LABS, “Augmented Reality Apps: The Future Real + Virtual,” 2013.

http://www.xcubelabs.com/blog/augmented-reality-apps-t he-future-is-real-virtual/ 